\title{
Recyclability Potential of Induction-Healable Porous Asphalt Mixtures
}

\author{
Pedro Lastra-González ${ }^{1, *(\mathbb{D}}$, Irune Indacoechea-Vega ${ }^{1}$, , Miguel A. Calzada-Pérez $^{2}$ and \\ Daniel Castro-Fresno ${ }^{1}$ (i) \\ 1 GITECO Research Group, Universidad de Cantabria, Avda. de Los Castros s/n., 39005 Santander, Spain; \\ irune.indacoechea@unican.es (I.I.-V.); castrod@unican.es (D.C.-F.) \\ 2 GCS Research Group, Universidad de Cantabria, Avda. de Los Castros s/n., 39005 Santander, Spain; \\ calzadam@unican.es \\ * Correspondence: lastragp@unican.es; Tel.: +34-942-20-39-43; Fax: +34-942-20-17-03
}

Received: 12 October 2020; Accepted: 24 November 2020; Published: 28 November 2020

\begin{abstract}
The potential recyclability of healable asphalt mixtures has been analyzed in this paper. A healable porous asphalt mixture with steel wool fibers was artificially aged in order to assess its recyclability. This mixture was used as reclaimed asphalt in a new porous asphalt mixture, whose mechanical and healing capacities were studied and compared with the behavior of the original porous asphalt mixture. The quantity of reclaimed asphalt mixture added was $40 \%$; besides, in order to recover the properties of the aged binder, and incorporate the last advances in the recyclability of bituminous mixtures, a rejuvenator was also added (SYLVAROAD ${ }^{\mathrm{TM}}$ RP1000). The voids test, Cantabro particle loss test, water sensitivity test, stiffness test, and fatigue resistance test were performed to mechanically study the experimental mixture, while the last one (fatigue resistance test) was also used to assess its healing capacity. The results have shown that the healing capacity of the original healable porous asphalt mixture is maintained with similar mechanical performance.
\end{abstract}

Keywords: porous asphalt; healing; induction heating; rejuvenator; recyclability

\section{Introduction}

Highlights:

- Porous mixture with healing capacity was artificially aged

- It was used as RA to design a new porous asphalt mixture with healing capacity

- Rejuvenator was added to recover binder properties

- The mechanical and healing properties were not affected

Porous asphalt (PA) is a special type of bituminous mixture with a high percentage of voids (usually higher than 20\%). This fact makes this type of mixture especially suitable to increase the skid resistance, minimize aquaplaning, and decrease the noise emissions and the spray produced by the tires of vehicles [1]. They are also used as a surface layer to manage the water run-off and to improve the performance of permeable pavements used as Sustainable Drainage System [2,3]. However, this type of mixtures has two main disadvantages: the mortar ages more quickly because it is exposed to weather conditions due to the high percentage of voids, which also increases the stripping of the aggregates. Both processes produce raveling problems in the PA mixture, which is its typical type of failure, significantly shortening its useful life [4]. Besides, the PA mixture can show clogging problems, these mixtures have to be laid in locations with a high percentage of rainy days; otherwise, voids are going to be filled with dust and stones, and later water is not able to drain into the PA mixture [5]. 
Induction heating has been shown to be an effective method to increase the useful life of PA mixtures, decreasing the small fissures which produce raveling of PA mixtures [6]. Although in the past, most of the reclaimed asphalt was used in unbound layers as an aggregate, now, the priority is the reuse of the material in the same conditions as the original mixture, considering not only the aggregate fraction but also the bitumen, and if possible, maintaining special properties as in the case of healable mixtures. Recyclability is one of the main environmental parameters when dealing with bituminous mixtures. In this sense, from approximately $40 \%$ of the available reclaimed asphalt (RA) in 2007 (500,000 t) used in unbound layers [7], the figure has been reduced to $1 \%$ in 2015, being possible to reuse approximately $400,000 \mathrm{t}$ in bituminous mixtures [8]. However, the recyclability of the healable mixtures has not been deeply studied, neglecting whether they can be reused, keeping the healable properties is a main environmental and economic parameter.

The chance to reduce the consumption of the main raw materials, both natural aggregates and bitumen, makes the reuse of RA key to reducing the environmental impact of asphalt pavements. In this sense, existing limitations for the use of RA in surface layers and specific mix types are being surpassed and these uses are starting to be allowed $[9,10]$.

Regarding the incorporation of RA, the main traditional methods depend on the temperature (hot or cold recycling) and the location of the production process (in-situ or in-plant) [11]. However, the development reached by some chemical products and composite materials gives way to new trends in the reuse of RA such as the replacement of natural aggregate by by-products, the addition of rejuvenators to recover the properties of the aged bitumen, and the use of warm mix asphalt technologies [12-19].

\section{Scope and Objective}

To ensure the positive environmental and economic impact of reusing RA, the field performance of the recycled mixture should be guaranteed [20]. Besides, in the case of the induction heating technique, the healable capacity of the recycled asphalt mixture should also be checked. As the induction-healing of asphalt mixtures is a relatively new technique [21], a deep study to analyze their recyclability incorporating metal particles is needed, which would improve their economic analysis.

The induction heating technique has been used with RA to know its behavior when the mixture is aged due to weather conditions [22]; however, its recycling performance, including the re-use of residual metallic particles inside the RA, and the addition of a rejuvenator, have not been deeply analyzed. Although the aging process depends on a lot of parameters [23], induction-healable PA mixes was artificially aged according to the AASHTO R 30-02 to be used as RA in new induction healable PA mixes.

The impact of $40 \%$ of this RA made by healable PA mixture in the mechanical and healing performance of the new mixtures was evaluated to check the recyclability of this type of mixture.

\section{Materials}

Conventional aggregates traditionally used in Spain were used. For the coarse fraction, a porphyry igneous rock (ophite) was used while for the fine and filler fraction, it was limestone. The properties of these materials are included in Table 1. Concerning the binder, a 50/70 penetration grade bitumen was used. Its main properties are shown in Table 2.

Steel wool fibers that can be heated by induction were added to the asphalt mixture. These fibers were supplied with less than $0.5 \mathrm{~mm}$ diameter and $6 \mathrm{~mm}$ maximum length (Figure 1).

In addition, a bio-based rejuvenator (SYLVAROAD ${ }^{\mathrm{TM}} \mathrm{RP1000)}$ ) commercially available on the market, was added to the RA in order to restore the chemical properties of the aged bitumen. The main properties of the rejuvenator are shown in Table 3. The selection of this additive, SYLVAROAD ${ }^{\mathrm{TM}}$ RP1000, was based on previous positive experiences in the restoration of aged bitumen in asphalt mixtures with a high percentage of RA [24,25]. 
Table 1. Properties of aggregates.

\begin{tabular}{ccc}
\hline & Result & Standard \\
\hline Ophite & & \\
\hline Angels coefficient & 16 & EN 1097-2 \\
Specific weight $\left(\mathrm{g} / \mathrm{cm}^{3}\right)$ & 2.937 & EN 1097-6 \\
Polished stone value (PSV) & $>56$ & EN 1097-8 \\
Flakiness Index $(\%)$ & 8 & EN 933-3 \\
\hline Limestone & & \\
\hline Angels coefficient & 28 & EN 1097-2 \\
Specific weight $\left(\mathrm{g} / \mathrm{cm}^{3}\right)$ & 2.725 & EN 1097-6 \\
Sand equivalent & 78 & EN 933-8 \\
\hline
\end{tabular}

Table 2. Binder properties.

\begin{tabular}{ccc}
\hline & Result & Standard \\
\hline Penetration at $25^{\circ} \mathrm{C}(\mathrm{dmm})$ & 57 & EN 1426 \\
Softening point $\left({ }^{\circ} \mathrm{C}\right)$ & 51.6 & EN 1427 \\
Fraass point $\left({ }^{\circ} \mathrm{C}\right)$ & -13 & EN 12593 \\
Density $\left(\mathrm{g} / \mathrm{cm}^{3}\right)$ & 1.035 & EN 15326 \\
\hline
\end{tabular}

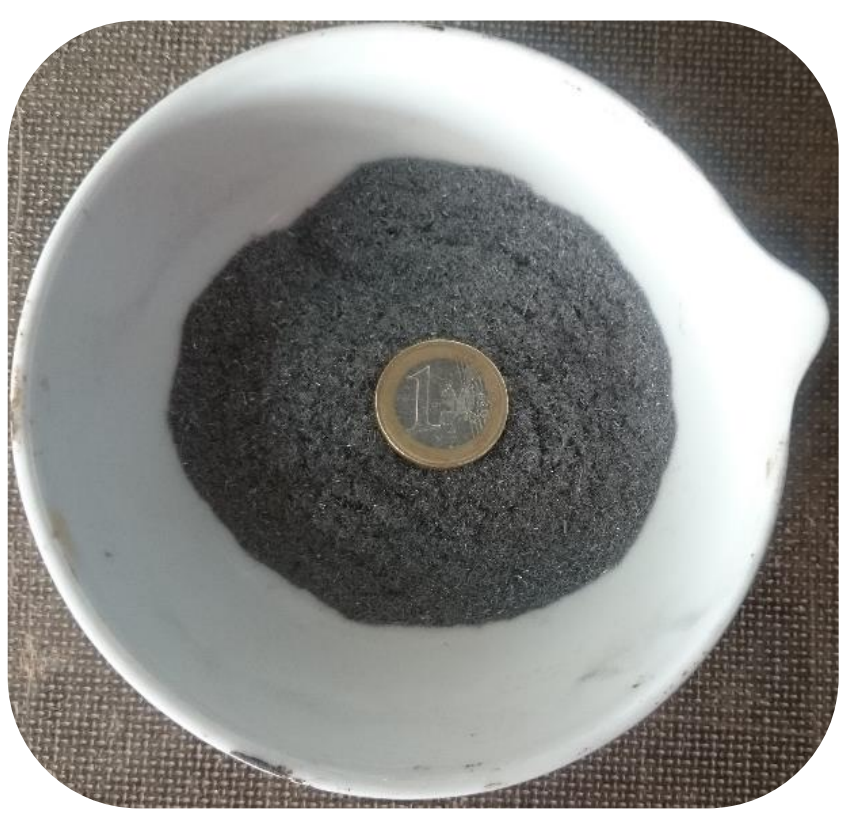

Figure 1. Steel wool fibers.

Table 3. Properties of the rejuvenating additive.

\begin{tabular}{cccc}
\hline Flash Point $\left({ }^{\circ} \mathrm{C}\right)$ & Viscosity at $60{ }^{\circ} \mathrm{C}(\mathrm{Cst})$ & Density $\left(\mathrm{g} / \mathrm{cm}^{3}\right)$ & Cloud Point $\left({ }^{\circ} \mathrm{C}\right)$ \\
\hline$>280$ & 22 & 0.93 & $<-25$ \\
\hline
\end{tabular}

\section{Methodology}

The original induction-healable PA mixture artificially aged in this study to produce the induction-healable RA was designed and characterized in previous work [6]. The composition included steel wool fibers (1.1\% w/waggregates) and an optimal percentage of bitumen of $4.5 \% w / w_{\text {mixture }}$. The aging procedure was carried out according to the AASHTO R 30-02. This standard includes two 
phases. The first consisting of heating loose mixture at $135^{\circ} \mathrm{C}$ for $4 \mathrm{~h}$ and the second, of heating compacted samples at $85^{\circ} \mathrm{C}$ for five days.

The dosage of this RA is presented in Table 4. The properties of the binder after the aging process are shown in Table 5 where the hardening effect in the bitumen can be observed (both binders, virgin and aged, were originally the same).

Table 4. Original PA16 dosage.

\begin{tabular}{cc}
\hline Material & $\% w / w$ \\
\hline Ophitic (coarse aggregate) & 85.7 \\
Limestone (fine aggregate + filler) & 13.2 \\
Steel Fibers & 1.1 \\
Bitumen/mixture (\%) & 4.5 \\
\hline
\end{tabular}

Table 5. Properties of recovered binder.

\begin{tabular}{cc}
\hline & RA Binder \\
\hline Penetration $(\mathrm{dmm})$ & 25 \\
Ring and ball $\left({ }^{\circ} \mathrm{C}\right)$ & 63.6 \\
Penetration index & 0.2 \\
\hline
\end{tabular}

As explained before, for the evaluation of the recyclability of asphalt mixtures incorporating metal particles, a new induction-healable PA mixture was designed including $40 \%$ of the induction-healable RA. The new mixture was evaluated in terms of its mechanical and healing performance and compared with those of the original PA mixture. It should be noted that for the design of the new PA mixture, $100 \%$ contribution of the metallic particles contained in the RA was considered. This means that $40 \%$ fewer amount of metallic particles were added to the new mixture. Concerning the rejuvenator, the dosage was $5 \% w / w$ in the binder from RA. It was sprayed on the hot RA before its incorporation into the mixer.

In order to evaluate the mechanical performance of the asphalt mixture, the voids test (EN 12697-8), the Cantabro loss particle test in dry conditions (EN 12697-17), and the water sensitivity test (EN 12697-12) were carried out. Four samples per type of mixture were used in these tests. Also, the dynamic performance, in terms of the stiffness (EN 12697-26) and the fatigue resistance (EN 12697-24) was assessed. For the dynamic tests, at least 14 replicates were tested. Both tests were carried out at $20^{\circ} \mathrm{C}$; in the case of the stiffness test, using a fixed strain of $50 \mu \mathrm{m} / \mathrm{m}$ and frequencies from $0.1 \mathrm{~Hz}$ to $30 \mathrm{~Hz}$. On the other hand, the fatigue test was done at $30 \mathrm{~Hz}$ and the failure criterion was considered when the cycle $(\mathrm{N})$ for which the sample presented half the initial stress for the imposed strain $(\varepsilon)$ is achieved. The fatigue laws were calculated with the next equation ( $a$ and $b$ are constant):

$$
\varepsilon(\mathrm{m} / \mathrm{m})=a \cdot 10^{-3} \cdot \mathrm{N}(\text { Cycles })^{b}
$$

Concerning the healing performance evaluation, the fatigue test was selected to damage the asphalt sample. In this study, the same methodology as in [6], was used to damage and heal the specimens. According to the results of this previous work, in order to maximize the healing ratio, the treatment should be done when the sample is near the failure criteria (initial stiffness is reduced by half). The healing ratio (H.R.) is defined as the ratio between the total sum of cycles before and after the healing treatment, and the number of cycles that the mixture is able to withstand when no healing treatment is applied. Thus, a healing ratio higher than 1 means that the fatigue life of the asphalt mixture was increased.

$$
\text { H.R. }=\frac{\text { Cycles } 1 \text { (before healing })+ \text { Cycles } 2(\text { after healing })}{\text { Cycles of failure }}
$$


Figure 2 presents the configuration of the healing treatment, with the induction machine, the coil, the thermal camera, and the asphalt sample.

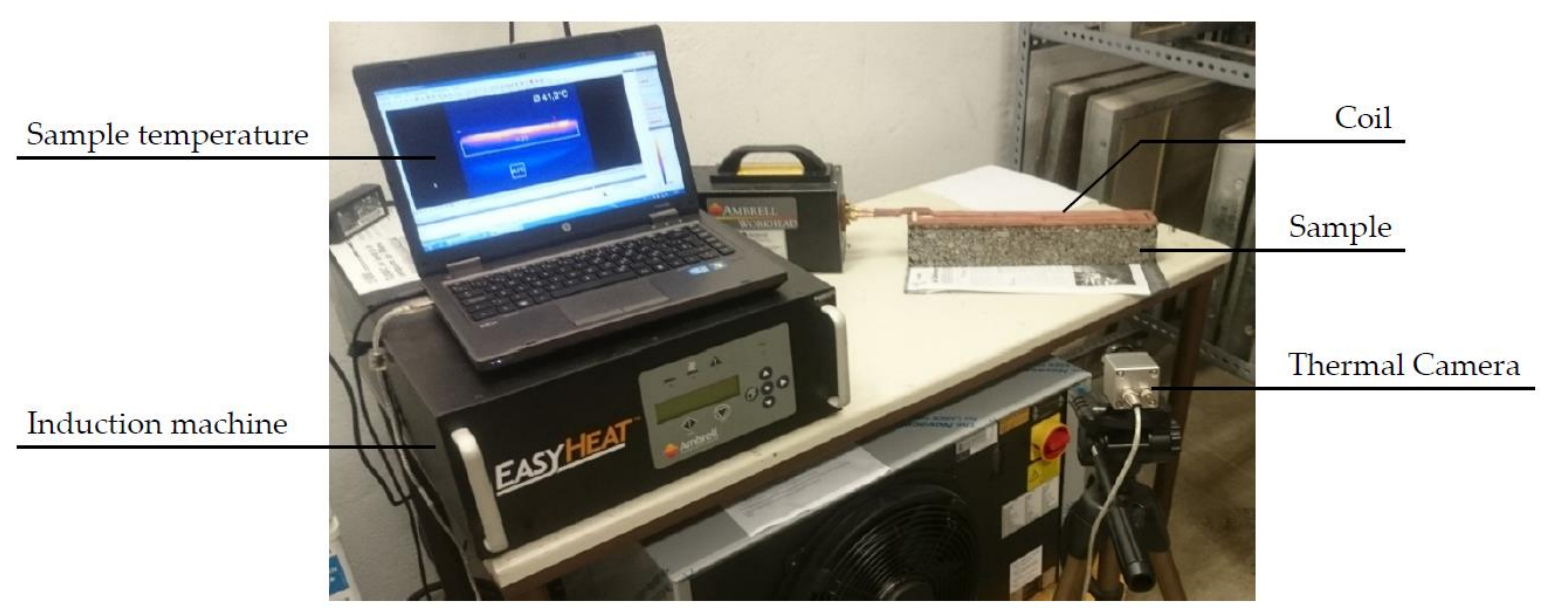

Figure 2. Induction machine with the fatigue test configuration.

The treatment was applied to seven samples when the stiffness of the sample was $55 \%$ of its initial value. The samples were healed applying an electric current of $500 \mathrm{~A}$ for $150 \mathrm{~s}$. The maximum temperature reached was around $110^{\circ} \mathrm{C}$ in all cases.

\section{Results and Discussion}

\subsection{Design of the New PA Mixture}

The particle size distribution of the aggregates of the new PA mixture, including the highest and lowest limits requested by the Spanish standards [26], are presented in Figure 3. The percentage of each material used in its design is included in Table 6 . The optimal percentage of virgin binder was $4 \%$ $w / w_{\text {mixture }}$

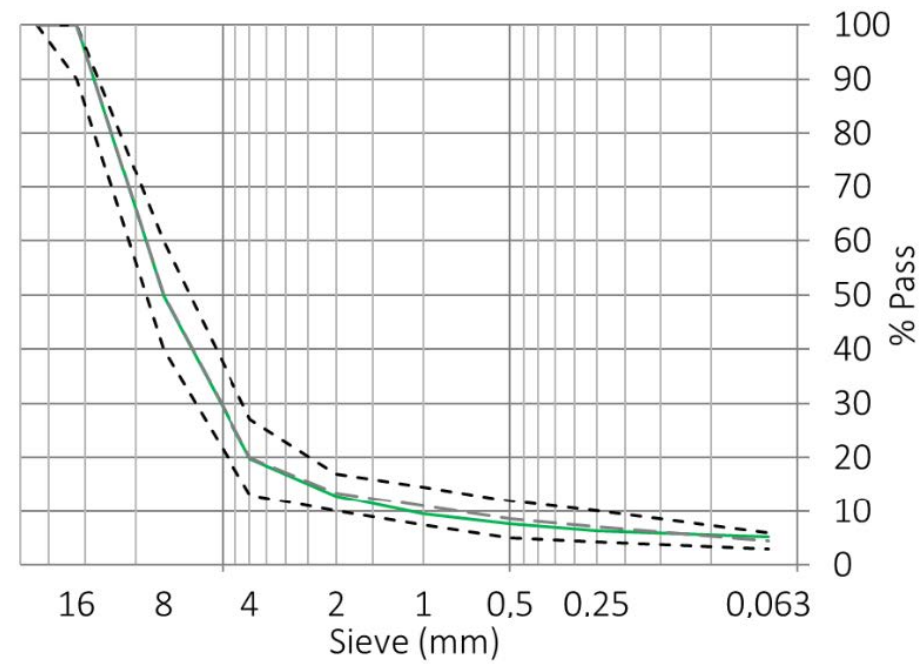

Figure 3. Particle size distribution of new PA mixture with RAP. 
Table 6. New PA16 recycled dosage.

\begin{tabular}{cc}
\hline Material & $\% \boldsymbol{w} / \boldsymbol{w}$ \\
\hline Ophitic (coarse aggregate) & 52.7 \\
Limestone (fine aggregate + filler) & 7.2 \\
RA (aged healing PA mixture) & 39.2 \\
New steel fibers & 0.8 \\
\hline
\end{tabular}

\subsection{Mechanical Performance}

As explained before, the following tests were performed to assess the mechanical performance of the new PA mixture incorporating the healable RA: air void content, particle loss, water sensitivity, stiffness, and fatigue resistance. The results are presented and discussed in this section.

Regarding the air void content and the particle loss of the experimental and the reference PA mixture, the results are shown in Table 7. Concerning the air void content, a similar result is obtained in both cases, over $20 \%$, which is considered the minimum value to ensure good drainage in a porous asphalt mixture. The particle loss test result of the experimental PA mixture can be considered better than the one of the reference mixture because its mass loss is lower, and it has a slightly higher percentage of voids. The result is very positive considering that, according to the Spanish normative [26], the maximum mass loss is limited to $20 \%$ for the highest traffic level and to achieve this requirement, polymer-modified bitumen is normally needed, which is not the case of the research presented in this paper.

Table 7. Voids and Cantabro particle loss test.

\begin{tabular}{ccc}
\hline & Experimental PA & Original PA \\
\hline Density $\left(\mathrm{g} / \mathrm{cm}^{3}\right)$ & $2.097 \pm 0.017$ & $2.121 \pm 0.006$ \\
Voids in mixture $(\%)$ & $22.1 \pm 0.6$ & $20.8 \pm 0.2$ \\
Loss particle $(\%)$ & $17.5 \pm 1.7$ & $20.9 \pm 6.9$ \\
\hline
\end{tabular}

The water sensitivity test of the experimental and reference mixes was performed according to the EN 12697-12 and the results are shown in Table 8. The water effect on the experimental mixture, measured by the Indirect Tensile Strength Ratio (ITSR), is very close to the original mix. However, it should be noted that the Indirect Tensile Strength (ITS) obtained by the mixture containing recycled material is notably lower. This is likely due to the increase in the void content observed before (Table 7). The rejuvenator could also affect the water damage if it softens the binder somehow.

Table 8. Water sensitivity test result.

\begin{tabular}{|c|c|c|c|c|}
\hline & \multicolumn{2}{|c|}{ Experimental PA } & \multicolumn{2}{|c|}{ Original PA } \\
\hline & Dry & Wet & Dry & Wet \\
\hline I.T.S. (KPa) & $1040.0 \pm 70.2$ & $864.1 \pm 60.1$ & $1319.8 \pm 43.5$ & $1125.9 \pm 18.7$ \\
\hline I.T.S.R. (\%) & \multicolumn{2}{|c|}{83} & \multicolumn{2}{|c|}{85} \\
\hline
\end{tabular}

Finally, the stiffness and the fatigue resistance tests are carried out according to the EN12697-26 Annex B and EN12697-24 Annex D, respectively. Although the stiffness test results obtained for the experimental PA mixtures are quite similar to those of the original PA mixture (Table 9), a slight downward trend is observed for all frequencies. This minor difference can be related to the higher percentage of voids previously reported. 
Table 9. Stiffness of PA mixtures.

\begin{tabular}{ccccccccc}
\hline & \multicolumn{2}{c}{ Experimental PA } & \multicolumn{3}{c}{ Original PA } \\
\hline Frequency & $\begin{array}{c}\text { Dynamic Modulus } \pm \\
\text { Deviation }\end{array}$ & $\begin{array}{c}\text { Phase Angle } \pm \\
\text { Deviation }\end{array}$ & $\begin{array}{c}\text { Dynamic Modulus } \pm \\
\text { Deviation }\end{array}$ & $\begin{array}{c}\text { Phase Angle } \pm \\
\text { Deviation }\end{array}$ \\
\hline $\mathbf{( H z )}$ & $\mathbf{( M P a )}$ & \multicolumn{2}{c}{$\left.\mathbf{(}^{\circ}\right)$} & \multicolumn{2}{c}{$\mathbf{( M P a )}$} & $\left.\mathbf{(}^{\circ}\right)$ \\
\hline 0.1 & 278 & 21 & 49.1 & 3 & 343 & 17 & 49.4 & 1 \\
\hline 0.2 & 358 & 47 & 47.6 & 3 & 413 & 29 & 48.9 & 1 \\
\hline 0.5 & 486 & 63 & 46.2 & 2 & 548 & 48 & 47.4 & 1 \\
\hline 1 & 617 & 78 & 44.8 & 2 & 684 & 68 & 45.7 & 1 \\
\hline 2 & 785 & 87 & 42.9 & 1 & 866 & 98 & 43.4 & 1 \\
\hline 5 & 1083 & 103 & 40.1 & 1 & 1177 & 152 & 40.3 & 1 \\
\hline 8 & 1283 & 119 & 38.2 & 1 & 1384 & 189 & 38.3 & 1 \\
\hline 10 & 1383 & 123 & 37.5 & 1 & 1486 & 206 & 37.7 & 1 \\
\hline 20 & 1774 & 156 & 34.9 & 0 & 1882 & 272 & 34.7 & 1 \\
\hline 30 & 2055 & 179 & 33.4 & 0 & 2161 & 315 & 32.8 & 1 \\
\hline
\end{tabular}

In the case of the fatigue resistance, the fatigue law of both mixes is also comparable (Table 10), the strain characteristic of the experimental PA mixture being slightly higher than that of the original PA mixture, which is coherent with the lightly lower stiffness that this mixture has shown. However, it should be noted that the experimental PA mixture presented a lower initial stiffness $\left(\mathrm{S}_{0}\right)$, even lower than the modulus obtained in the stiffness test at the same frequency, which is probably related to some variability among the samples.

Table 10. Results of fatigue resistance test of PA mixtures.

\begin{tabular}{ccccc}
\hline & $\begin{array}{c}\mathbf{S}_{\mathbf{0}} \\
(\mathbf{M P a})\end{array}$ & $\begin{array}{c}\text { Strain-Characteristic } \\
(\mu \mathrm{m} / \mathbf{m})\end{array}$ & Fatigue Line & $\mathbf{R}^{\mathbf{2}}$ \\
\hline Experimental PA & 1700 & 186.0 & $\varepsilon(\mathrm{m} / \mathrm{m})=4.502 \cdot 10^{-3} \cdot \mathrm{N}^{-0.2306}$ & 0.81 \\
\hline Original PA & 2103 & 171.9 & $\varepsilon(\mathrm{m} / \mathrm{m})=4.060 \cdot 10^{-3} \cdot \mathrm{N}^{-0.2289}$ & 0.93 \\
\hline \multicolumn{7}{c}{${ }^{*} 10^{6}$ cycles. }
\end{tabular}

\subsection{Healing Performance}

As explained before, in the methodology section, the healing performance was evaluated by damaging the asphalt sample with the fatigue test and later healing it via induction heating. In order to define the deformation to be used in the fatigue test, the fatigue law of the experimental PA mixture was determined through the four-bending fatigue test. Thus, a reference deformation of $175 \mu \mathrm{m} / \mathrm{m}$ (Figure 4) was selected, which resists 1.3 million cycles to failure according to the fatigue law. As established in [6], the optimum moment to apply the healing treatment corresponds to the moment when the stiffness of the mixture is around 55\% of its initial value. So, the aim of this procedure was to be closer to this ratio (55\%), applying a deformation of $175 \mu \mathrm{m} / \mathrm{m}$ for 1 million cycles instead of 1.3 million. Figure 4 presents the characteristics of the fatigue test performed (lines are not proportional in order to clarify the procedure). The black lines represent the two deformations $(175 \mu \mathrm{m} / \mathrm{m}$ and $186 \mu \mathrm{m} / \mathrm{m})$ and their cycles until failure applying the test conventionally. The green lines are the deformation and cycles actually applied in the first stage to assess the healing performance.

Therefore, in the first stage of the healing performance test (Table 11), the samples were subjected to 1 million cycles before healing. The stiffness reached was $57.4 \%$, which is very close to the aim of 
$55 \%$. In the second phase, after applying the healing treatment, the fatigue test was carried out until failure. The average healing ratio obtained was 2.1.

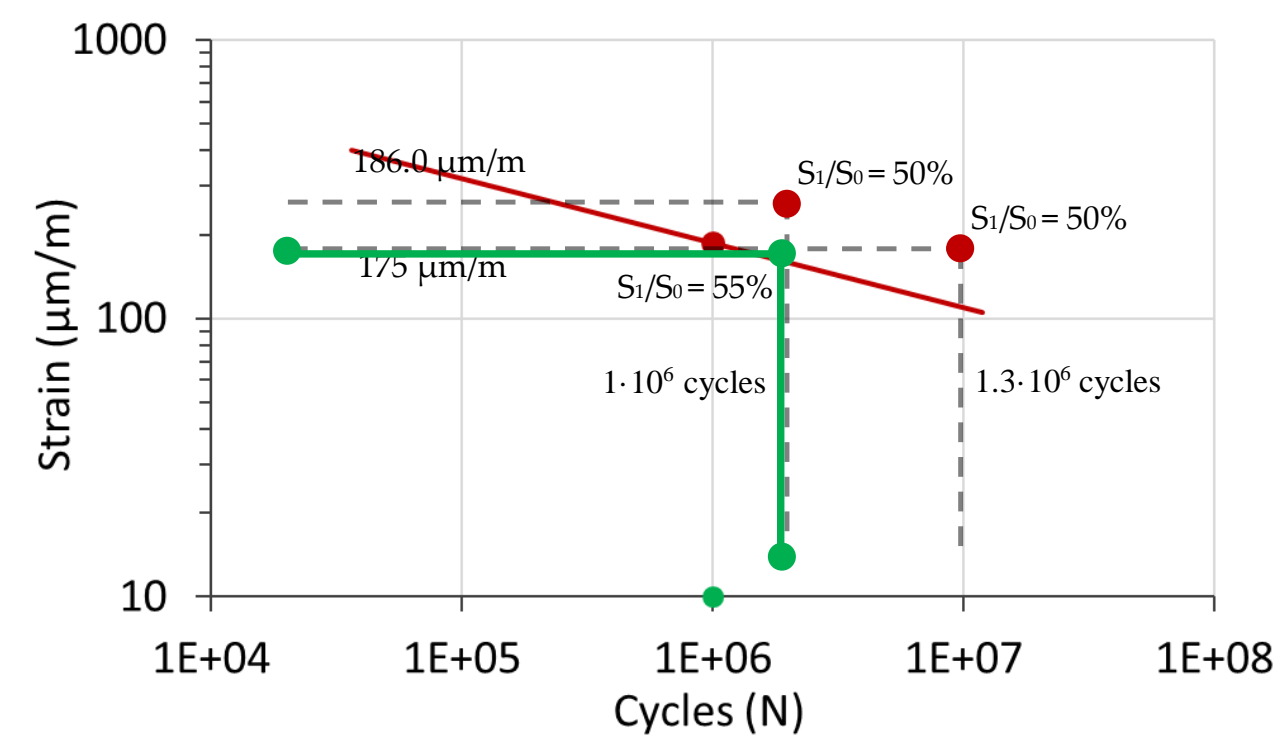

Figure 4. Fatigue law and selected deformation to perform healing assessment.

Table 11. Healing performance test.

\begin{tabular}{|c|c|c|c|c|c|c|c|c|c|}
\hline \multirow[b]{2}{*}{ Cycles } & \multicolumn{2}{|c|}{ Fatigue 1} & \multirow[b]{2}{*}{$\begin{array}{c}\text { Deviation } \\
\mathrm{S}_{1} / \mathrm{S}_{0} \\
(\%)\end{array}$} & \multicolumn{4}{|c|}{ Fatigue 2} & \multicolumn{2}{|c|}{ Final } \\
\hline & $\begin{array}{c}\mathcal{E} \\
(\mu \mathrm{m} / \mathrm{m})\end{array}$ & $\begin{array}{c}\mathrm{S}_{1} / \mathrm{S}_{0} \\
(\%)\end{array}$ & & $\begin{array}{c}\varepsilon \\
(\mu \mathrm{m} / \mathrm{m})\end{array}$ & $\begin{array}{c}\mathrm{S}_{1} / \mathrm{S}_{0} \\
(\%)\end{array}$ & Cycles & $\begin{array}{l}\text { Deviation } \\
\text { Cycles }\end{array}$ & $\begin{array}{c}\text { Total } \\
\text { Cycles }\end{array}$ & H.R. \\
\hline $1,000,000$ & 174.0 & 57.4 & 2.0 & 173.9 & 50.0 & $1,800,484$ & 392,643 & $2,800,484$ & 2.1 \\
\hline
\end{tabular}

A slight variability inherent to this test can be observed in Figure 5, where the healing ratio achieved in all the samples is plotted against their stiffness after the first fatigue test. In this same figure, the results obtained in [6] for the original PA mixture were added to compare the healing performance of both mixtures. It should be noted that in this case, different deformation levels were applied. According to the results in Figure 5, it is clear that recycling healable asphalt mixtures including a rejuvenator is possible without losing the healing capacity of the new mixes produced.

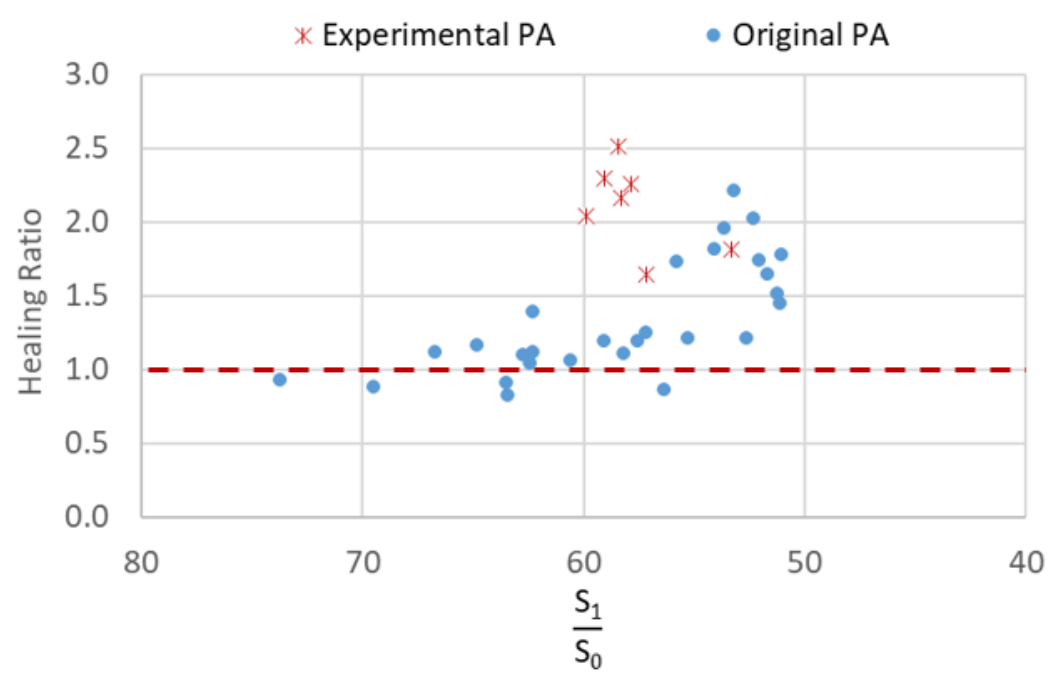

Figure 5. Healing ratio of each sample. 
Although the original PA sample recycled as RA is different from the one designed for this study, the experimental PA, it can be seen in Figure 5 that the healing capacity is still working based on the procedure followed in the research.

\section{Conclusions}

In this paper, the recyclability potential of porous asphalt mixes that can be induction healed is assessed. To do so, a healable porous asphalt mixture was artificially aged to be used as reclaimed asphalt in a new porous asphalt mixture. This new porous asphalt mixture was designed incorporating $40 \%$ of this reclaimed asphalt with a rejuvenator. The amount of metallic particles of the reclaimed asphalt fraction was considered to contribute $100 \%$ to the new mixture, so only $60 \%$ of new steel wool fibers were added to the new mixture. The mechanical and healing performance of the new mixture was evaluated, and the main conclusions are summarized as follows:

- In terms of mechanical performance, the recyclability of healable porous asphalt mixes is demonstrated. In this research, the mechanical behavior of the recycled porous asphalt mixture with $40 \%$ of reclaimed asphalt was quite similar to the original, although both mixtures slightly differ in composition. The experimental mixture has slightly increased its resistance against raveling despite it having a higher percentage of voids. Concerning the water sensitivity test, the experimental mixture showed lower resistances than the original mixture, although the water damage ratio is quite similar. This result is also conditioned by the higher percentage of voids of the experimental mixture. Concerning its stiffness and fatigue resistance, a similar mechanical performance was observed.

- With regard to the healing performance, the recyclability of healable porous asphalt mixes is also demonstrated. The recycled mixture incorporating $40 \%$ reclaimed asphalt maintained and even improved the healing capacity of the original healable porous asphalt mixture. This difference is probably due to the small modifications between both mixes, such as the total bitumen or voids content, and the effect of the rejuvenator.

- The addition of the rejuvenator proved to be adequate in terms of both the mechanical and healing performance point of view.

Author Contributions: Conceptualization, P.L.-G., I.I.-V., M.A.C.-P., and D.C.-F.; methodology, investigation, and writing-original draft preparation, P.L.-G. and I.I.-V.; writing-review and editing, and supervision, M.A.C.-P., and D.C.-F.; funding acquisition, D.C.F. All authors have read and agreed to the published version of the manuscript.

Funding: The research presented in this paper is part of the HEALROAD project financed by the Infravation program (an ERA-NET Plus on Infrastructure Innovation) under the grant agreement No. 31109806.0003. Funding partners of the Infravation 2014 Call were: Ministerie van Infrastructuur en Milieu, Rijkswaterstaat, Bundesministerium für Verkehr, Bau und Stadtentwicklung, Danish Road Directorate, Statens Vegvesen Vegdirektoratet, Trafickverket-TRV, Vegagerdin, Ministere de l'Ecologie du Developpement Durable et de l'Energie, Centro para el Desarrollo Tecnológico Industrial, Anas S.P.S, Netivei Israel-National Transport Infrastructure Company LTD and Federal Highway Administration USDOT.

Acknowledgments: The authors want to thank the consortium members of the HEALROAD project for their valuable contributions. The HEALROAD project has been carried out by the University of Nottingham, German Federal Highways Research Institute (BASt), Heijmans Integrale projecten B.V., SGS INTRON B.V., European Union Road Federation (ERF), and University of Cantabria. The authors wish to acknowledge and especially thank Laurent Porot (KRATON Corporation) for his collaboration.

Conflicts of Interest: The authors declare no conflict of interest.

\section{References}

1. Liu, Q.; Cao, D. Research on material composition and performance of porous asphalt pavement. J. Mater. Civ. Eng. 2009, 21, 135-140. [CrossRef]

2. Andrés-Doménech, I.; Hernández-Crespo, C.; Martín, M.; Andrés-Valeri, V.C. Characterization of wash-off from urban impervious surfaces and SuDS design criteria for source control under semi-arid conditions. Sci. Total Environ. 2018, 612, 1320-1328. [CrossRef] [PubMed] 
3. Barrett, M.E.; Kearfott, P.; Malina, J.F., Jr. Stormwater quality benefits of a porous friction course and its effect on pollutant removal by roadside shoulders. Water Environ. Res. 2006, 78, 2177-2185. [CrossRef] [PubMed]

4. Andrés-Valeri, V.C.; Rodriguez-Torres, J.; Calzada-Perez, M.A.; Rodriguez-Hernandez, J. Exploratory study of porous asphalt mixtures with additions of reclaimed tetra pak material. Constr. Build. Mater. 2018, 160, 233-239. [CrossRef]

5. Andrés-Valeri, V.C.; Marchioni, M.; Sañudo-Fontaneda, L.A.; Giustozzi, F.; Becciu, G. Laboratory assessment of the infiltration capacity reduction in clogged porous mixture surfaces. Sustainability 2016, 8, 751. [CrossRef]

6. Lastra-González, P.; Indacoechea-Vega, I.; Calzada-Pérez, M.A.; Vega-Zamanillo, Á.; Castro-Fresno, D. Assessment of induction heating in the performance of porous asphalt mixtures. Road Mater Pavement Des. 2020, 21, 2302-2320. [CrossRef]

7. E. European Asphalt Pavement Association. Asphalt in Figures; 2007; pp. 1-5. Available online: http: //www.eapa.org/usr_img/asphalt/AsphaltinFigures2007.pdf (accessed on 6 July 2018).

8. E. European Asphalt Pavement Association. Asphalt in Figures; 2015; pp. 1-9. Available online: https: //eapa.org/wp-content/uploads/2018/07/2015.pdf (accessed on 25 November 2020).

9. de la Roche, C.; Van de Ven, M.; Planche, J.P.; Van den Bergh, W.; Grenfell, J.; Gabet, T.; Mouillet, V.; Porot, L.; Farcas, F.; Ruo, C. Hot recycling of bituminous mixtures. RILEM State Art Rep. 2013, 9, 361-428. [CrossRef]

10. C. de Estudios y Experimentación de Obras Públicas (CEDEX), Reciclado de Pavimentos Asfálticos. 2015. Available online: http://www.cedexmateriales.es/upload/docs/es_recicladodepavimentosasfalticosnov2015. pdf (accessed on 25 November 2020).

11. Sánchez, A.E. Efecto del Tipo de Aditivo en el Comportamiento de Mezclas Bituminosas a Diferentes Temperaturas de Fabricación y Compactación. Ph.D. Thesis, Universidad de Cantabria, Cantabria, Spain, 2012. Available online: https://www.educacion.gob.es/teseo/mostrarRef.do?ref=996474 (accessed on 25 November 2020).

12. Baghaee, M.T.; Baaj, H. The use of rejuvenating agents in production of recycled hot mix asphalt: A systematic review. Constr. Build. Mater. 2016, 114, 805-816. [CrossRef]

13. Abed, A.; Thom, N.; Presti, D.L. Design considerations of high RAP-content asphalt produced at reduced temperatures. Mater. Struct. Constr. 2018, 51. [CrossRef]

14. Lastra-González, P.; Calzada-Pérez, M.A.; Castro-Fresno, D.; Indacoechea-Vega, I. Asphalt mixtures with high rates of recycled aggregates and modified bitumen with rubber at reduced temperature. Road Mater. Pavement Des. 2018, 19. [CrossRef]

15. Rodríguez-Fernández, I.; Lastra-González, P.; Indacoechea-Vega, I.; Castro-Fresno, D. Recyclability potential of asphalt mixes containing reclaimed asphalt pavement and industrial by-products. Constr. Build. Mater. 2019, 195, 148-155. [CrossRef]

16. Ouyang, J.; Zhao, Z.; Yang, H.; Zhang, Y.; Tang, A. Large-scale synthesis of sub-micro sized halloysite-composed CZA with enhanced catalysis performances. Appl. Clay Sci. 2018, 152, 221-229. [CrossRef]

17. Corrado, A.; Polini, W. Measurement of high flexibility components in composite material by touch probe and force sensing resistors. J. Manuf. Process. 2019, 45, 520-531. [CrossRef]

18. Lu, D.X.; Saleh, M. Laboratory evaluation of warm mix asphalt incorporating high RAP proportion by using evotherm and sylvaroad additives. Constr. Build. Mater. 2016, 114, 580-587. [CrossRef]

19. Wang, F.; Xie, Z.; Liang, J.; Fang, B.; Piao, Y.; Hao, M.; Wang, Z. Tourmaline-Modified FeMnTiOx Catalysts for Improved Low-Temperature NH3-SCR Performance. Environ. Sci. Technol. 2019, 53, 6989-6996. [CrossRef] [PubMed]

20. Aurangzeb, Q.; Al-Qadi, I.L. Asphalt pavements with high reclaimed asphalt pavement content: Economic and environmental perspectives. Transp. Res. Rec. 2014, 2456, 161-169. [CrossRef]

21. Xu, S.; García, A.; Su, J.; Liu, Q.; Tabaković, A.; Schlangen, E. Self-Healing Asphalt Review: From Idea to Practice. Adv. Mater. Interfaces 2018. [CrossRef]

22. Gómez-Meijide, B.; Ajam, H.; Lastra-González, P.; Garcia, A. Effect of ageing and RAP content on the induction healing properties of asphalt mixtures. Constr. Build. Mater. 2018, 179. [CrossRef]

23. Bocci, E.; Prosperi, E.; Mair, V.; Bocci, M. Ageing and Cooling of Hot-Mix-Asphalt during Hauling and Paving-A Laboratory and Site Study. Sustainability 2020, 12, 8612. [CrossRef]

24. Porot, L.; Broere, D.; Wistuba, M.; Grönniger, J. Asphalt and binder evaluation of asphalt mix with $70 \%$ reclaimed asphalt. Road Mater. Pavement Des. 2017, 18, 66-75. [CrossRef] 
25. Tuner, P.; Taylor, A.; Tran, N. Laboratory Evaluation of SYLVAROAD ${ }^{\mathrm{TM}}$ RP 1000 Rejuvenator 2015. Available online: http://www.eng.auburn.edu/research/centers/ncat/files/reports/2015/rep15-03.pdf (accessed on 25 November 2020).

26. Minitserio de Fomento; Spanish Goverment. Orden FOM/2523/2014, Por la Que se Actualizan Determinados Artículos del Pliego de Prescripciones Técnicas Generales Para Obras de Carreteras y Puentes, Relativos a Materiales Básicos, a Firmes y Pavimentos, y a Señalización, Balizamiento y Sistemas de Contención de Vehículos. 2015. Available online: https://www.boe.es/boe/dias/2015/01/03/pdfs/BOE-A-2015-48.pdf (accessed on 25 November 2020).

Publisher's Note: MDPI stays neutral with regard to jurisdictional claims in published maps and institutional affiliations.

(C) 2020 by the authors. Licensee MDPI, Basel, Switzerland. This article is an open access article distributed under the terms and conditions of the Creative Commons Attribution (CC BY) license (http://creativecommons.org/licenses/by/4.0/). 